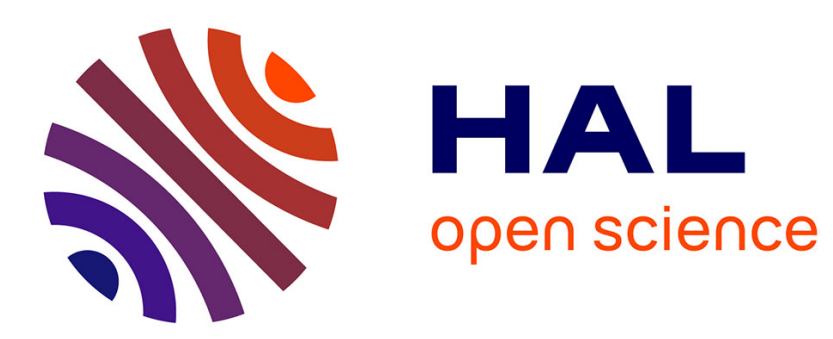

\title{
A Lagrangian particle method for the treatment of impact and penetration problems
}

\author{
H. Bung, P. Galon, M. Lepareux, A. Letellier
}

\section{To cite this version:}

H. Bung, P. Galon, M. Lepareux, A. Letellier. A Lagrangian particle method for the treatment of impact and penetration problems. Journal de Physique IV Proceedings, 1994, 04 (C8), pp.C8-507C8-513. 10.1051/jp4:1994879 . jpa-00253440

\section{HAL Id: jpa-00253440 https://hal.science/jpa-00253440}

Submitted on 1 Jan 1994

HAL is a multi-disciplinary open access archive for the deposit and dissemination of scientific research documents, whether they are published or not. The documents may come from teaching and research institutions in France or abroad, or from public or private research centers.
L'archive ouverte pluridisciplinaire HAL, est destinée au dépôt et à la diffusion de documents scientifiques de niveau recherche, publiés ou non, émanant des établissements d'enseignement et de recherche français ou étrangers, des laboratoires publics ou privés. 


\title{
A Lagrangian particle method for the treatment of impact and penetration problems
}

H. Bung, P. Galon, M. Lepareux and A. Letellier

Commissariat à l'Energie Atomique, Centre d'Etudes de Saclay, DRN/DMT/SEMT/DYN, 91191 Gif-sur-Yvette cedex, France

\begin{abstract}
Résumé: Un nouvel algorithme a été developpé dans le logiciel de PLEXUS du système CASTEM pour traiter le contact solide/solide ou solide/fluide par une formulation Lagrangienne, en représentant un des corps (le plus friable) par un ensemble de "billes" dont la cohésion est assurée par une loi d'interaction entre les particules.
\end{abstract}

\begin{abstract}
A new algorithm was developed in the PLEXUS code of Castem system : this algorithm enables to treat solid/solid or solid/fluide contacts, using for one body a "marble cluster" the cohesion of which is ensured by an interaction law acting on the cluster particles.
\end{abstract}

\section{INTRODUCTION}

The Finite Element Method is a well suited tool to take into account the complexity of the geometries; the non linear behaviour laws, the contact modelling in the study of such problems. The Lagrangian algorithm is in its essence relatively simple and well suited for impact problems between solids. But it has drawbacks when the mesh is subject to large deformations and distorsions. One or various remeshing are thus required during the computation. The Eulerian or Euler-Lagrange formulation helps avoid these large distorsions but is more difficult to set up and presents difficulties when the boundary conditions are of lagrangian kind.

To solve these problems frequently encountered during collision between two structures, a new algorithm was developed in the PLEXUS code of Castem system : this algorithm enables to treat solid/solid or solid/fluid contacts, using for one body an updated lagrangian formulation, the other one being represented by a "marble cluster" the cohesion of which is ensured by an interaction law acting on the cluster particles. The motion of the different particles is no longer hindered by the mesh distorsion : the marble connectivity is calculated throughout the computation according to the local state of the structure. 


\section{NUMERICAL MODEL}

\subsection{Cluster geometry}

Given a volume, we try to fill it up with identical and equidistant marbles. At first glance the compact hexagonal network leads to the most compact filling up. We will keep this arrangement in the following :
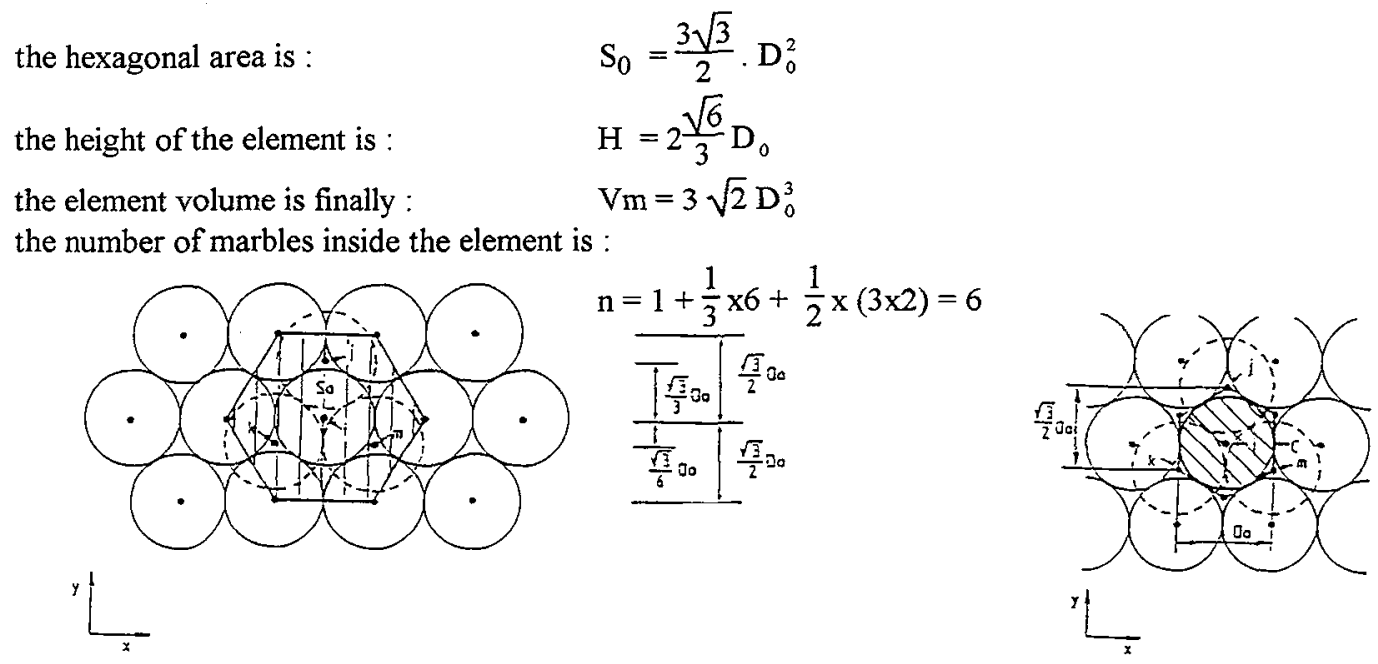

In their equilibrium state, the marbles make up a compact hexagonal network. Each node is then in contact with 12 neihbouring marbles. Each node of this network is associated to a single node element with 3 degrees of freedom the mass of which is :

$$
\mathrm{M}_{0}=\frac{\rho_{0} \cdot V_{m}}{n}=\frac{\sqrt{2}}{2} \rho_{0} \mathrm{D}_{0}^{3}
$$

\subsection{Behavior law}

\subsubsection{Determination of the volumic mass}

The relative variation of the volume $\mu$ is :

$$
\mu=\frac{\rho}{\rho_{0}}-1=\frac{V_{0}}{V}-1
$$

where $\rho, V$ : density and specific volume at time $t$

$\rho_{0}, V_{0}:$ density and specific volume at time $t=0$

The density of material surrounding marble $i$ is obtained in the following manner :

1) We define $\mu_{1}$ as : $\quad \mu_{1}=\left[\frac{D_{0}}{\bar{D}}\right]^{3}-1$

where $\bar{D}$ is the mean distance between $\mathrm{i}$ and the neighbouring marbles.

2) To avoid two marbles getting too close without generating repulsive forces, we define a second variable:

$$
\mu_{2}=\frac{D_{0}}{D}-\delta
$$

where $\mathrm{D}=\mathrm{D}_{\mathrm{ik}}$ is the distance between marble $\mathrm{i}$ and a neigbouring one $\mathrm{k}$

$\delta$ depends on cluster geometry. 
The density of the i-marble is then :

$$
\begin{array}{ll}
\mu & \mu=\max \left(\mu_{1}, \mu_{2}\right) \\
& \rho=(\mu+1) \rho_{0}
\end{array}
$$

\subsubsection{Pressure calculus}

The normal stress along the segment joining 2 nodes is :

$$
\sigma=s+p I
$$

where $\mathbf{s}$ : stress deviator ( in case of a perfect fluid, $s=0$ )

$\mathrm{p}$ : hydrostatic pressure

Besides, the hydrostatic pressure is related to other parameters by an equation of state :

where $e$ is the specific energy

$$
p=f(\rho, e, \ldots)
$$

In the case of an acoustic behavior, we write the following equation of state :

where $\mathrm{c}$ is the sound speed

$$
p=\Delta \rho c^{2}=\left(\rho-\rho_{0}\right) c^{2}
$$

\begin{tabular}{|c|c|c|c|}
\hline where & $\alpha=1$ & when & $D \leq \beta_{1} D_{0}$ \\
\hline & $\begin{array}{l}\alpha=\frac{D-\beta_{2} D_{0}}{\beta_{1} D_{0}-\beta_{2} D_{0}} \\
\alpha=0\end{array}$ & $\begin{array}{l}\text { when } \\
\text { when }\end{array}$ & $\begin{array}{l}\beta_{1} D_{0} \leq D \leq \beta_{2} D_{0} \\
\beta_{2} D_{0} \leq D\end{array}$ \\
\hline
\end{tabular}

When two marbles get more and more distant, the pressure becomes negative and generates attractive forces. In the case of a liquid, this pressure becomes equal to zero when it reaches a limit : it is the cavitation phenomenon. To take this effect into account, we balance the pressure by :

$$
\mathrm{P}^{\prime}=\alpha \mathrm{P}
$$

$\beta_{1}$ and $\beta_{2}$ depend on material properties.

\subsection{Force calculus}

The forces acting on the nodes are proportional to the normal stress $\sigma$ ( $\sigma=-p I$ for perfect fluids). The normal force acting on node $i$ is: $\quad F_{n}=-S p n$

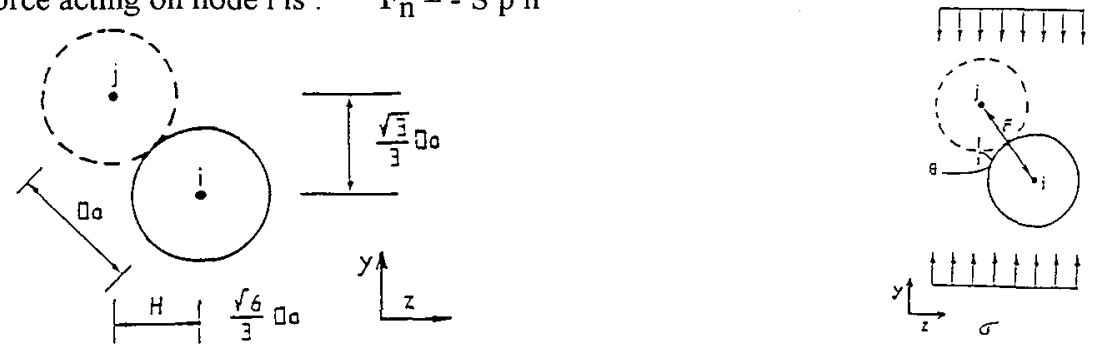

The projection on $\mathrm{OZ}$ of the forces exerted by the 3 marbles $j, k, m$ on marble $i$ is :

$3 \mathrm{~F} \cos \theta=\mathrm{pA}$

with

$$
\cos \theta=\frac{\sqrt{6}}{3}
$$

A : contact area projected on XOY which corresponds to the hexagon circumscribed to the cercle $\mathrm{C}$

$$
A=\frac{\sqrt{3}}{2} D_{p}^{2}
$$


For node $\mathrm{j}$ in interaction with node $\mathrm{i}$ studied, we calculate :

$$
\begin{aligned}
& \mathrm{x}^{\mathrm{k}_{\mathrm{ij}}}=\mathrm{x}_{\mathrm{j}}-\mathrm{x}_{\mathrm{i}} \mathrm{k}_{\mathrm{i}} \quad \mathrm{k}=1,3 \\
& D^{2}=\sum^{3}\left(x_{j i}^{k}\right)^{2} \\
& \mathrm{k}=1 \\
& D_{p}^{2}=\frac{\bar{D}^{3}}{D} \\
& F_{n}=-\frac{\sqrt{2}}{4} D_{p}^{2} \cdot P \cdot n
\end{aligned}
$$

It was seen (in most cases) that :

$$
\begin{aligned}
\mu & =\left[\frac{D_{0}}{\bar{D}}\right]^{3}-1 \\
& \Leftrightarrow \quad \bar{D}^{3}=\frac{\mathrm{D}_{0}^{3} /(1+\mu)}{\bar{D}^{3}} \\
\text { We then take : } & D_{p}^{2}=\frac{\mathrm{D}_{0}{ }^{3} / \mathrm{D}(1+\mu)}{D}
\end{aligned}
$$

we have finally:

$$
F_{n}^{i}=-\frac{\sqrt{2}}{4} \frac{D_{0}^{3}}{D(1+\mu)} \cdot P n
$$

The strength $F_{n}$ acts along the segment connecting both the nodes in interaction. For each node $i$ of the marble cluster, we accumulate the interaction strengths generated by the marbles neighbouring the node.

We then get $a_{k}=\dot{x}_{j i} / D$ which are the director cosinus of the segment connecting nodes $i$ and $j$. Finally the force applied to node $i$ resulting from the interaction between nodes $i$ and $j$, and expressed in the global reference system is :

$$
\begin{aligned}
& F^{i}{ }_{1, j}=a_{1} F_{n} \quad \text { along } x \\
& \mathrm{Fi}_{2, \mathrm{j}}=\mathrm{a}_{2} \mathrm{Fi}_{\mathrm{n}}^{\mathrm{i}} \quad \text { along } \mathrm{y} \\
& \mathrm{Fi}_{3, j}=\mathrm{a}_{3} \mathrm{Fi}_{\mathrm{n}} \quad \text { along } \mathrm{z}
\end{aligned}
$$

The total force acting on node $i$ and generated by all the marbles in interaction at time $t$ with node $i$ is :

$$
\begin{aligned}
& F_{1}^{i}=\sum_{j=1}^{n v} F_{1, j}{ }^{i} \\
& F_{2}^{i}=\sum_{j=1}^{n v} F_{2, j}{ }^{i} \\
& F_{3}^{i}=\sum_{j=1}^{n v} F_{3, j}^{i}
\end{aligned}
$$

$\mathrm{nv}$ being the number of marbles in interaction with $\mathrm{i}$ at time $\mathrm{t}$.

\subsection{Contact forces}

The calculus of the contact forces is identical to the one for the sliding 3D surfaces (see [7]). We assume that the master element and marble impact is equivalent to an elastic shock of 2 points. The gravity centre A of the penetrated face nodes is of mass $m_{T}$ and has a velocity $V_{T}$. 


$$
\begin{aligned}
& \mathrm{m}_{\mathrm{T}}=\sum_{\mathrm{i}=1}^{\mathrm{nbn}} \mathrm{m}_{\mathrm{i}} \\
& \mathrm{V}_{\mathrm{T}}=\left(\sum_{\mathrm{i}=1}^{\mathrm{nbn}} \mathrm{m}_{\mathrm{i}} \mathrm{V}_{\mathrm{i}}\right) / \mathrm{m}_{\mathrm{T}}
\end{aligned}
$$

where nbn is the number of nodes of the face of the master element.

The marble (point $B$ ) is of mass $m_{0}$ and has a velocity $V_{0}$. The gravity centre velocity $V_{G}$ of both the 2 points $\mathrm{A}$ and $\mathrm{B}$ is :

$$
\mathrm{V}_{\mathrm{G}}=\frac{\mathrm{m}_{0} \mathrm{~V}_{0}+\mathrm{m}_{\mathrm{T}} \mathrm{V}_{\mathrm{T}}}{\mathrm{m}_{0}+\mathrm{m}_{\mathrm{T}}}
$$

In a reference system connected to the gravity centre for each point, the velocity changes sign after the shock : one can thus write :

$$
V_{j}^{\prime}-V_{G}=-\left(V_{j}-V_{G}\right)
$$

The impulse Q transfered to the slave node is :

$$
\mathrm{Q}=\sum_{\mathrm{i}=1}^{\mathrm{nbn}} \mathrm{q}_{\mathrm{i}}
$$

with

$$
\mathrm{q}_{\mathrm{i}}=\left(\mathrm{V}_{\mathrm{i}}-\mathrm{V}_{\mathrm{i}}^{\prime}\right) \mathrm{m}_{\mathrm{i}}=\frac{\Delta t_{1}+\Delta t_{2}}{2} \cdot \frac{F a}{n b n}
$$

$\Delta t_{1}:$ time step of the current cycle

$\Delta t_{2}:$ time step of the next cycle

hence

$$
\begin{aligned}
& \mathrm{Q}=\sum_{\mathrm{i}=1}^{\mathrm{nbn}} 2 \mathrm{~m}_{\mathrm{i}}\left(\mathrm{V}_{\mathrm{i}}-\mathrm{V}_{\mathrm{G}}\right)=\frac{\Delta t_{1}+\Delta t_{2}}{2} \cdot F a \\
& \mathrm{~F}_{\mathrm{a}}=\frac{4}{\Delta \mathrm{t}_{\mathrm{l}}+\Delta \mathrm{t}_{2}} \cdot\left(\mathrm{m}_{\mathrm{T}}\left(\mathrm{V}_{\mathrm{T}}-\mathrm{V}_{\mathrm{G}}\right)\right)
\end{aligned}
$$

The calculated force $\mathrm{Fa}$ is then projected along the normal $\mathrm{n}$ to the element face, and added to the exterior force of the corresponding node

For the slave node (marble)

$$
\mathrm{F}_{\mathrm{B}}=-(\mathrm{Fa} \cdot \mathrm{n}) \cdot \mathrm{n}
$$

For each node of the penetrated face $\quad F_{A}=(F a, n) \cdot n / n b n$

\section{EXAMPLES}

Various behaviours have been implemented in the PLEXUS software for the marble elements :

- acoustic fluid material

- PUFF material (hydrodynamic behaviour for high velocity phenomena)

- linear elastic material

A few examples are treated here using these new elements.

\subsection{Bending of beam (mixed mesh)}


This example illustrates the possibility to connect a zone modelled by marbles to another one modelled using classical finite elements.

A beam is modelled by a mixed mesh made up of 1134 marble elements and 2112 6-node prismatic elements (see figure 1).

This beam is fixed at one end, and subject to a vertical impulsive load at the other end.

\subsection{Impact of water jet on a plate}

This example clearly shows the assets of marble modelling. The aim is to study the behaviour of a plate subject to a water jet at a high velocity $(140 \mathrm{~m} / \mathrm{s})$. The computation would be impossible in Lagrangian, as the mesh would undergo to large distorsions. The Euler-Lagrange approach would require too many elements : we needed to model all the zone the fluid could occupy at any time of the simulation.

In this case, the plate is modelled using classical shell elements ( 1600 shells), while the fluid is modelled by 2720 marble elements. The computation is performed in 10000 time steps, and requires $4500 \mathrm{CPU}$ seconds on an IBM RS6000/590. Figure 2 shows the deformed states at various time steps.

\subsection{Perforation of a plate}

This time, the plate is represented by marble elements, while the projectile is modelled with classical finite elements. The marble modelling allows an easy simulation of the perforation phenomenon (see figure 3 ).

\section{CONCLUSION}

In case of very important deformations, classical Lagrangian description becomes insufficient if the body blows up into fragments. The connectivity being fixed, certain body movements are not allowed. The model presented here and implemented in PLEXUS code seems well suited to treat such problems.

The encouraging results, obtained with simple behavior laws (acoustic fluids, elastic material, interaction law between marbles programmable by user) allow us to envisage the introduction of more complex behaviour laws : steel with plasticity, concrete model, composites ...

\section{REFERENCES}

[1] G. JOHNSON, R. STRYK, Computations for solids with variable nodal connectivity for severe distorsions. IJNME, vol 23,509-522 (1986)

[2] G. JOHNSON, R. STRYK, Dynamic three dimensionnal computations for solids with variable nodal connectivity for severe distorsions.IJNME, vol 23,817-832 (1989)

[3] M. WILKINS, Use of Artificial Viscosity in Multidimensionnal Fluid Dynamic Calculations. Journal of Computational Physics, 36,281-303(1980)

[4] F. HARLOW, B. MEIXNER. The particle and Force Method for Dynamics, LAMS 2567, Los Alamos Scientific Laboratory (June 1961)

[5] M. LEPAREUX, B. SCHWAB, H. BUNG. PLEXUS: A General Computer Program for Fast Dynamic Analysis., Trans. 8th Int. Conf on SMiRT(North-Holland, Amsterdam, 1985) paper F 2/1

[6] H.BUNG, A. COMBESCURE, A. FORESTIER, M. LEPAREUX, P. GALON . Loi de comportement et modélisation des impacts. 3rd Inter. Conf. on Mech.and Phys. Behavior of Materials under Dynamic Loading (Strasbourg 1991)

[7] H.BUNG, M. LEPAREUX, P. GALON. Algorithme de traitement des surfaces de glissements (3D) dans le programme PLEXUS. Rapport DEMT/SEMT/LAMS/90-092 (1990) 
[8] P. GALON, H.BUNG. Programme PLEXUS: Loi de comportement pour une modélisation par des billes. Rapport DMT/91-255 (1991)

[9] P. GALON, H.BUNG, M. LEPAREUX. Programme PLEXUS: Remplissage d'un volume par des billes équidistantes. Rapport DMT/91-007 (1991)

[10] H.BUNG,P.GALON,M.LEPAREUXand A.COMBESCURE .A New Method For Treatment of Impact an Penetration Problems .Trans. 12th Int. Conf on SMiRT.(Germany, Stuttgart, 1993)
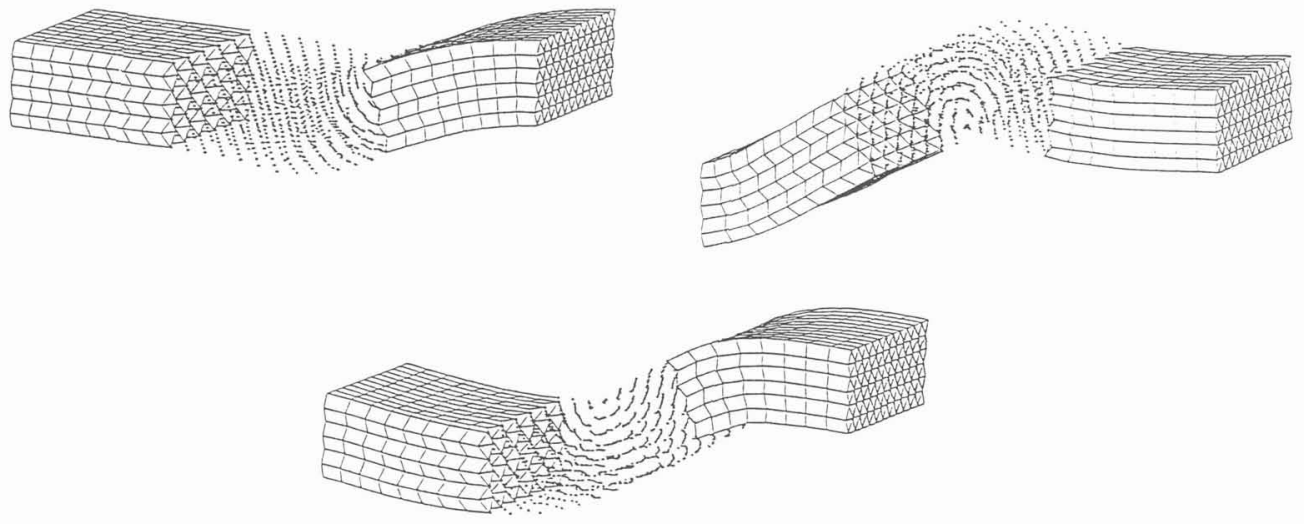

Figure 1 Bending of Beam

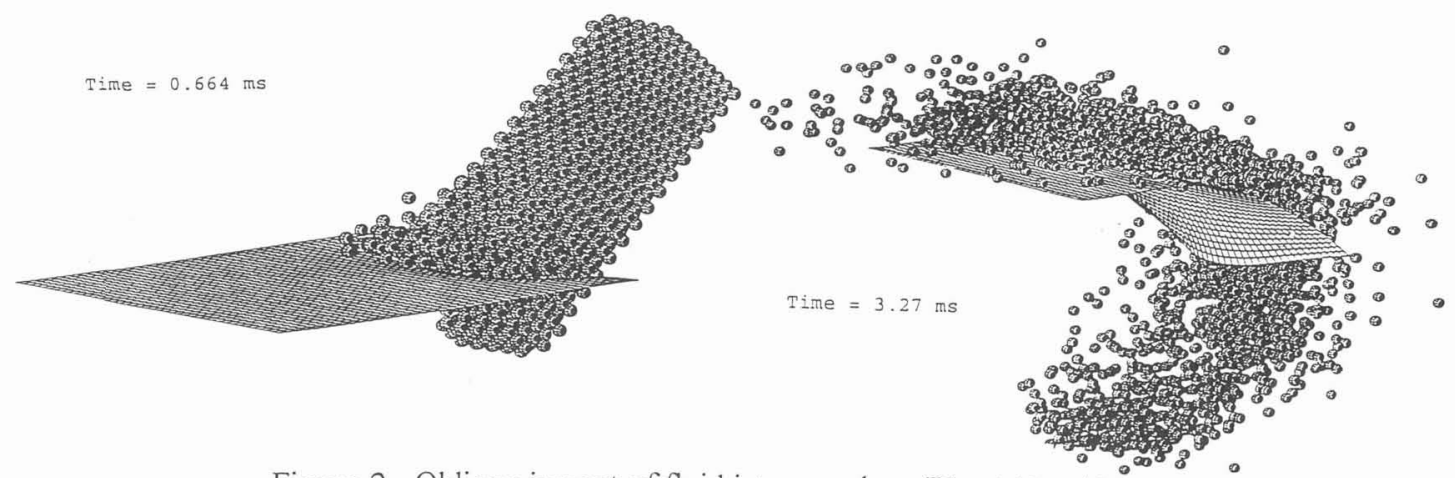

Figure 2 Oblique impact of fluid jet on a plate (V $=141 \mathrm{~m} / \mathrm{s}$ )
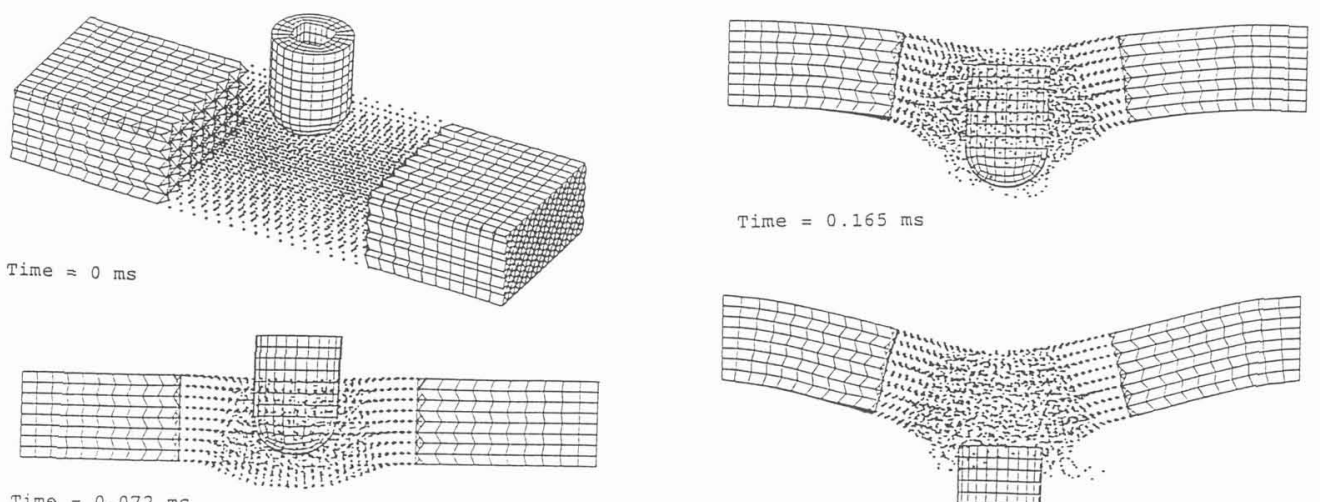

Time $=0.165 \mathrm{~ms}$

Figure 3 Perforation of a plate $(\mathrm{V}=1600 \mathrm{~m} / \mathrm{s})$

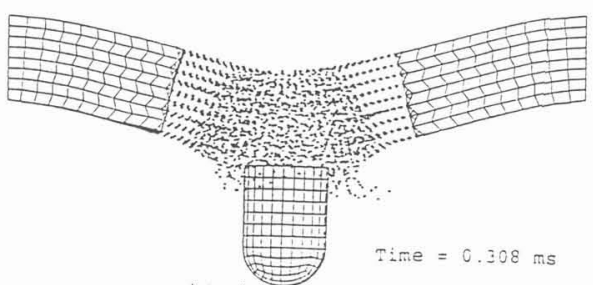

